\title{
EVALUATING LOCAL STRATEGIC PARTNERSHIPS - Theory and practice of change
}

\author{
Mike Geddes, Jonathan Davies and Crispian Fuller, The Local Government \\ Centre, University of Warwick
}

\section{Introduction}

Local Strategic Partnerships (LSPs) are a major recent innovation in English local Governance (Aulakh et al, 2002; Hastings, 2003). Their role is crucial to the success of a number of other government policies and initiatives, including neighbourhood renewal and Local Area Agreements, and more widely to the responsive and effective delivery of local public services. Drawing on material from the national evaluation of LSPs, this paper assesses the progress of LSPs. A 'theory of change' (ToC) approach was adopted to drive and give coherence to the diverse elements of this large scale and complex evaluation. The paper first outlines how the ToC approach was developed and utilised in the evaluation. The main findings from the evaluation are then presented and discussed. While the initial function of the ToC was to develop a logic chain representing a virtuous circle where governmental aspirations for LSPs are achieved, it soon became apparent that a 'vicious circle' model was needed too, in which partnerships do not function as intended. It is shown that elements of both the virtuous and vicious circle are necessary to explain actual policy outcomes. In conclusion the article reflects on the experience of the LSPs evaluation to draw some 
wider conclusions both about the strengths and weaknesses of the ToC approach and about Local Strategic Partnerships themselves.

\section{Local Strategic Partnerships and the National Evaluation of LSPs}

Local Strategic Partnerships are a major innovation in the pattern of local governance in England. An LSP is a body which:

- Brings together at a local level the different parts of the public sector as well as the private, business, community and voluntary sectors.

- Is a non-statutory, non-executive organisation.

- Operates at a level which enables strategic decisions to be taken yet is close enough to the grassroots to allow direct community engagement.

Initial guidance on the establishment of LSPs was issued by government in early 2001 (DETR 2001). Currently, LSPs have been set up in the vast majority of localities in England. In those 88 local authority areas containing the most deprived neighbourhoods in England, eligibility for Government funding from the Neighbourhood Renewal Fund (NRF), is conditional on the existence of an LSP and the production of a Local Neighbourhood Renewal Strategy (LNRS). However, most localities (in NRF areas or not) have reacted enthusiastically to the government's proposals, endorsing the rationale for collaborative governance.

Local partners working through an LSP are expected to act strategically to draw up a Community Strategy, as an agreed basis on which to take decisions and initiate actions which join up partners' activities across a range of issues, enabling each of 
them to meet their own targets and goals and tackle cross-cutting issues more effectively (Jones and Ward, 2002, Davies, 2005). The intention is that LSPs will ensure public services work better and are delivered in ways that meet the needs of local people, and that economic, social and physical regeneration is sustained - in both deprived and prosperous areas (Hastings, 2003). Hence, community strategies have recently been re-labelled 'Sustainable Community Strategies' by ODPM.

A continuing role for LSPs is outlined in the 2006 government consultation paper, Local Strategic Partnerships - Shaping their Future (ODPM 2006). The consultation positions LSPs as central to the delivery of effective Local Area Agreements (the new mechanism to improve and join up local service delivery), the development of strong local leadership and devolved decision-making, and a key driver of community engagement.

\section{Evaluating the progress of LSPs}

The objective of the National Evaluation of LSPs (henceforth, 'the evaluation') has been to evaluate LSP progress and provide support to LSPs and policy-makers at local, regional and central levels ${ }^{1}$. Commissioned only a year after the publication of the initial government guidance leading to the establishment of LSPs, the evaluation has covered all LSPs, in both those areas eligible for NRF funding, and in other areas. This has been a formative evaluation, focussed on processes and policy development but also preliminary impacts. This approach reflects government's view in commissioning the evaluation that LSPs need time to bed down and several years to implement their strategies. This is consistent with the findings of much research on 
partnerships which suggests that new policies and institutions can take a considerable time to become embedded (Marsh and Rhodes, 1992: Geddes and Benington, 2001; Sullivan and Skelcher, 2002).

The evaluation included a number of qualitative and quantitative elements, principally nine longitudinal case studies; eight action learning sets; two surveys of all LSPs, undertaken in 2002 and 2004; and a number of specific topic studies ${ }^{2}$. The scale and complexity of the evaluation was one of the major factors prompting the early adoption of a theory of change methodology, as a means of providing a common framework for the multiple components and outputs.

\section{Developing and deploying a theory of change in the LSPs evaluation}

The theory of change (TOC) approach draws on US work by Connell and Kubisch (1998); Chen (1990); and Weiss et al (1995). It is becoming widely used in UK policy evaluation studies (Mackenzie and Blamey, 2005; Sullivan, Barnes and Matka 2002) and has become a central element in the meta-evaluation of the LGMA (see for example Sullivan et al, 2003; Boyne et al, 2001). According to Weiss, a TOC maps the assumptions which underpin any policy intervention. It is:

...a system of social and behavioural assumptions that underlie a public policy which have been reformulated in the form of propositions. These propositions reflect the beliefs of policy makers about the cognitions, attitudes and behaviours of the policy's target group: the people whom the policy is to affect. 
Sullivan and Stewart (2006) note how the theories of change approach to evaluation 'was devised to meet the need for an evaluative approach that could accommodate the multi-level and many dimensional impacts of developing social and public policy interventions...... In such initiatives the task of linking action to outcomes is extremely complex and difficult.... The designers of theories of change argue that its emphasis on the 'systematic and cumulative study of the links between activities, outcomes and contexts of the initiative' diminishes the attribution problem in part through the prior specification of the various links by stakeholders in the intervention, 3 .

If the above is a quote, it should be separated and indented. And I'm not sure why there are four quotation marks here. If this is a quote within a quote, then "' should be used for the embedded quote instead of '.

The starting point for the development of a theory of change in the LSPs evaluation was a characterisation of the government's 'system of assumptions' about the role of LSPs. This revolved around the proposition that a framework of strategic partnership at the local level will create more inclusive and pluralist local governance, bringing together key organisations and actors (from the three spheres of state, market and civil society) to identify communities' top priorities and needs, and work with local people to provide them. This is consistent with the widely shared perception in the policy community of the advantages of partnership working as the way of achieving effective outcomes, and solutions to so-called 'wicked issues', by building trust, sharing knowledge and resources, and working collaboratively across boundaries. 
Within the evaluation, the main features of the theory of change were developed at an early stage, although refinements were made throughout the research process ${ }^{4}$. Figure 1 represents diagrammatically the 'system of assumptions' behind LSPs - the key links in the chain of causation which will determine the extent to which LSPs come to represent an effective element within the structures and processes of local governance. These can be described as follows:

\section{Figure 1: The theory of change}

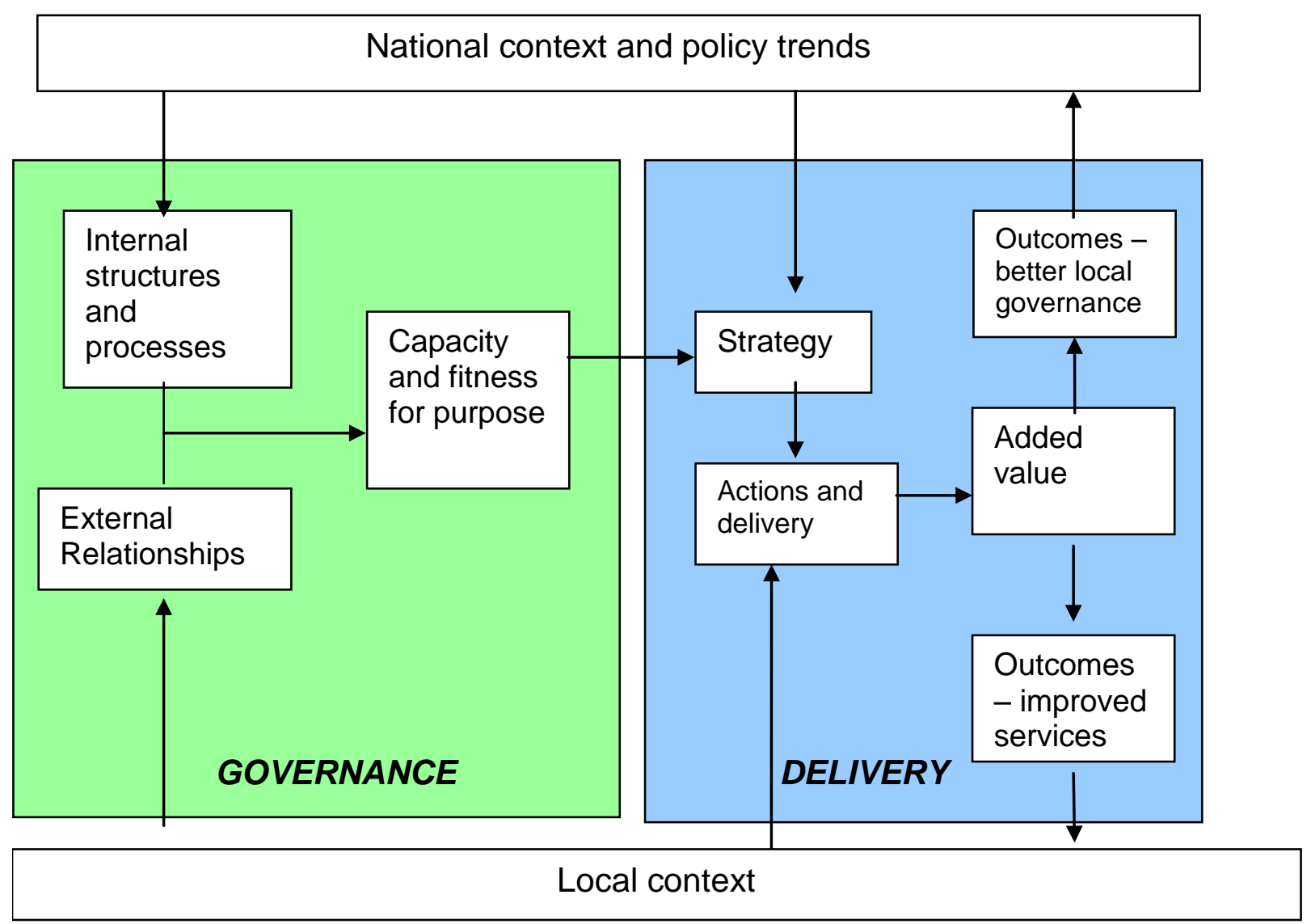


(a) LSPs are conditioned by the national policy context. The environment within which LSPs have emerged is one of major change in the contemporary forms of governance, with new institutions engineered in response to the perceived deficiencies of traditional, large bureaucratic 'silos'. Government seeks to create a more fragmented and fluid set of institutional structures and relationships, and new relationships between the state, the market and civil society.

b) The local policy contexts in which LSPs have developed are strongly conditioned by national trends, but will respond in differing ways as a result of local factors. The capacity of LSPs is conditioned by the history of past partnership working and the character and capacities of key partners.

c) The internal arrangements of the LSP (membership, leadership, structures and working practices, human and financial resources, performance management etc) then provide the framework within which these resources can be drawn upon, as the LSP develops its own identity and organisational culture.

d) The effectiveness of the LSP also depends crucially upon "networked governance' - the extent to which it is able to influence the actions of partners both among public service providers but also among other partners from the business, voluntary and community sectors, and with regional and subregional agencies 'above' the LSP and local communities and neighbourhoods 'below' it. 
(e) The combined impact of these factors (grouped together as 'governance' issues in Figure 1) will condition the extent to which an LSP is able to 'deliver' initially, by developing a set of local strategic perspectives - set out in the local community strategy and neighbourhood renewal strategy - which are agreed and owned by partners as a basis for action and implementation.

f) It is through these strategic interventions that improved services and more inclusive local governance are expected, with the LSP adding value to the activities of its partners.

This model can thus be seen to constitute a broad research hypothesis about the linked processes through which LSPs may achieve positive outcomes, which can be broken down into a set of linked theoretical propositions. These together involve assumptions about process; about vision and strategy; about action and outcomes; and about added value (Figure 2). Each of these theoretical principles can also be disaggregated into several empirical questions, as follows:

\section{Figure 2 Theoretical propositions and evaluation questions}

\begin{tabular}{|l|l|l|}
\hline Theoretical Proposition & Relates to: & \multicolumn{1}{l|}{ Empirical questions } \\
\hline $\begin{array}{l}\text { TP1 Inclusive processes of } \\
\text { negotiation and deliberation } \\
\text { generate a shared analysis, sense } \\
\text { of direction and capacity } \\
\text { which..... }\end{array}$ & Process & $\begin{array}{l}\text { Are the processes inclusive? } \\
\text { Is there an effective process of } \\
\text { deliberation and negotiation? } \\
\text { Is there a shared analysis? } \\
\text { Does the LSP have sufficient } \\
\text { capacity? }\end{array}$ \\
\hline $\begin{array}{l}\text { TP2 Unifies and adds clarity to } \\
\text { the local governance agenda and } \\
\text { priorities for service delivery, so } \\
\text { that.... }\end{array}$ & Vision and \\
\hline Strategy & $\begin{array}{l}\text { Has the LSP unified the local } \\
\text { governing agenda? } \\
\text { Have priorities for local } \\
\text { service delivery been set? }\end{array}$ \\
\hline
\end{tabular}




\begin{tabular}{|l|l|l|}
\hline $\begin{array}{l}\text { implement the vision/strategy, } \\
\text { both within their own } \\
\text { organisation, and multilaterally }\end{array}$ & Action & $\begin{array}{l}\text { vision/strategy? } \\
\text { Is there joined up action and } \\
\text { delivery? }\end{array}$ \\
\hline $\begin{array}{l}\text { TP4 In doing so, service delivery } \\
\text { and governance gains occur } \\
\text { because agencies have a better } \\
\text { understanding of what the } \\
\text { community wants and work } \\
\text { together to deliver }\end{array}$ & Outcomes & $\begin{array}{l}\text { Has better understanding of } \\
\text { priorities led to gains in service } \\
\text { delivery outcomes? } \\
\text { Has governance improved? }\end{array}$ \\
\hline $\begin{array}{l}\text { TP5 Recognition of the value } \\
\text { added by the LSP creates a } \\
\text { virtuous cycle of positive } \\
\text { outcomes and the embedding of } \\
\text { the LSP in the local governance } \\
\text { system }\end{array}$ & Added value & $\begin{array}{l}\text { Can the LSP be shown to add } \\
\text { value? } \\
\text { Are outcomes increasing and } \\
\text { sustainable? }\end{array}$ \\
\hline
\end{tabular}

Why has sustainability been dropped from the model? And shouldn't

outcomes/added value both be in TP4 - ie why have outcomes been separated from added value?

Clearly, any model such as this is a simplification, in several ways, and we return in our conclusions to some reflections on the limitations of a ToC approach.

Despite this, the model proved very helpful as a broad framework within which to progress the evaluation, both in drawing together findings from different component parts of the evaluation in driving and structuring consecutive stages of the research, and in reporting the results. The next section of the paper uses the framework of the theory of change to discuss the progress of LSPs.

\section{Findings from the evaluation - progress and problems for LSPs}

The discussion of the national evaluation findings is organised around the five theoretical propositions in the ToC model, outlined above.

TP1 - process: Inclusive processes of negotiation and deliberation generate a shared analysis, sense of direction and capacity ..... 
TP1 is essentially about agenda setting. Are LSPs arenas in which deliberation leads to agreement about the nature of local problems and potential solutions to those problems while generating new governing capacity?

The evaluation shows that LSPs have, in a relatively short time, established themselves as a recognised part of the institutional arrangements of modernised local governance. There is a broad positive consensus amongst most of those involved in LSPs about the principle and purpose of a local strategic partnership. To this extent, there is a shared analysis which contends that partnership working is the right institutional approach to local governance.

However there are very considerable differences in the extent to which LSPs can yet be said to have established robust and sustainable arrangements capable of sustaining a coordinated approach to local governance (see also Johnson and Osborne, 2003). There are important differences between NRF and non-NRF LSPs, and also between those in different kinds of local authority area (as well as between LSPs within these categories). The extent to which the LSP has been able to draw on a positive history of partnership working in each locality and whether it was set up relatively early or late are major factors. Considerable numbers of LSPs have established internal governance arrangements which seem both effective and inclusive. In others however structures and processes are either still relatively undeveloped, or not necessarily yet fully fit for purpose (Bailey, 2003). There are a number of significant factors in this respect. 
The strategic capacity of the LSP Board or Executive is important. Leadership is perceived to be a crucial element in determining the capacity of LSPs but the exercise of leadership within strategic partnerships remains extremely challenging, for example the question of when leadership ceases to be constructive and tips over into domination and exclusionary practices.

Substantial numbers of LSPs identified accountability as an area that needs strengthening. A key issue is the relationship of the LSP to local democratic processes, where the lynchpin role is that of the local councillor, yet many are not closely connected to, or in sympathy with, the LSP, and it is not clear that even where (mostly senior) councillors are actively and positively engaged with the LSP that they necessarily prioritise issues of democratic accountability. Recent studies have examined the potential for network democratisation (see Davies, 2006; Skelcher, 2005; Sorensen and Torfing, 2005) and they further illustrate the challenge facing LSPs, if they are to become fully inclusive; not only of local stakeholder interests, but of the interests of the wider local polity.

The extent to which LSPs have been successful so far in engaging partners and stakeholders varies greatly - both among LSPs, and between different categories of partner and stakeholder. For some LSPs, fundamental processes of engagement such as understanding partners' priorities and sharing information and data still remain largely on the 'to do' list. Many public sector partners are now making an increasing contribution within LSPs, but this engagement has not yet translated into securing change within partner organisations in line with LSP priorities. Other partners - 
including local councillors and the business sector - have yet to engage actively in many LSPs.

Questions about the capacity of LSPs include, on the one hand, how far structures and processes make it possible to take hard decisions, for example resolving tensions between conservation and development in one place, dealing with conflicts between competitiveness and cohesion in another. On the other hand, capacity issues are indicated by the very limited resources (of staff and of money) available to manage and run most LSPs, especially in non-NRF areas (Geddes, 2006; Fuller and Geddes, $2006)^{5}$

\section{TP2 Vision and Strategy: Unifies and adds clarity to the local governance agenda and priorities for service delivery ....}

The development of a shared strategic vision - where this has happened successfully - has often been both part of an institution-building process and the basis for action. For nearly all LSPs a central focus has been the development of the Community Strategy (and, in NRF areas, the local neighbourhood renewal strategy), although the extent to which the LSP (as opposed to the local authority) has been in the lead has varied considerably, as has the degree to which the CS goes beyond 'motherhood and apple pie' to map out a clear and distinctive strategic vision which lays the basis for collaborative and focuses action by partners. A shared analysis may, for example, be achieved on a superficial level by denying the existence of a contradiction between competitiveness and cohesion and manoeuvres of this kind, which generate a superficial consensus, are not dependent on organisational strength as such. The themed architecture of many LSPs may serve to compartmentalise and create space 
between competing interest groups (see also Lowndes and Sullivan, 2003). On the other hand, an elaborate institutional architecture may be the pre-condition for bringing contending parties together in a common space and facilitating deliberation between them. In some LSPs, squabbles over the distribution of NRF monies have impeded partnerships in developing a shared vision.

\section{TP3 Implementation: Partners will then implement the vision/strategy, both within their own organisation, and multilaterally.....}

Inevitably, in their early years, the establishment of effective governance arrangements has been a primary concern for LSPs, and indeed can be regarded as a sine qua non without which significant action and outcomes will not occur - partners sometimes say that their LSPs are 'on the cusp' of delivery (Davies, 2005). Nonetheless, there has been considerable pressure on LSPs - from local partners as well as government - to begin to deliver as quickly as possible, so that often the processes of building the LSP have had to go hand in hand with action (Geddes, 2006).

As Figure 3 shows, LSPs have become involved in many areas of activity. The greater government requirements of, and support for, NRF LSPs means that in general they have developed more substantial activity and made more progress across most issues (not just in tackling deprivation) than elsewhere. Many non-NRF LSPs have also developed initiatives on a range of issues, from transport to rural development and from economic development to environmental sustainability, and there is a clear relationship between the 'maturity' of the LSP partnership and the amount of progress 
made. At the same time, there is a 'tail' of LSPs (mostly but not exclusively nonNRF) where activity so far is limited. Moreover, LSPs may claim credit for activities carried out by one or more partners that is in no way dependent on the presence of an overarching strategic partnership. 


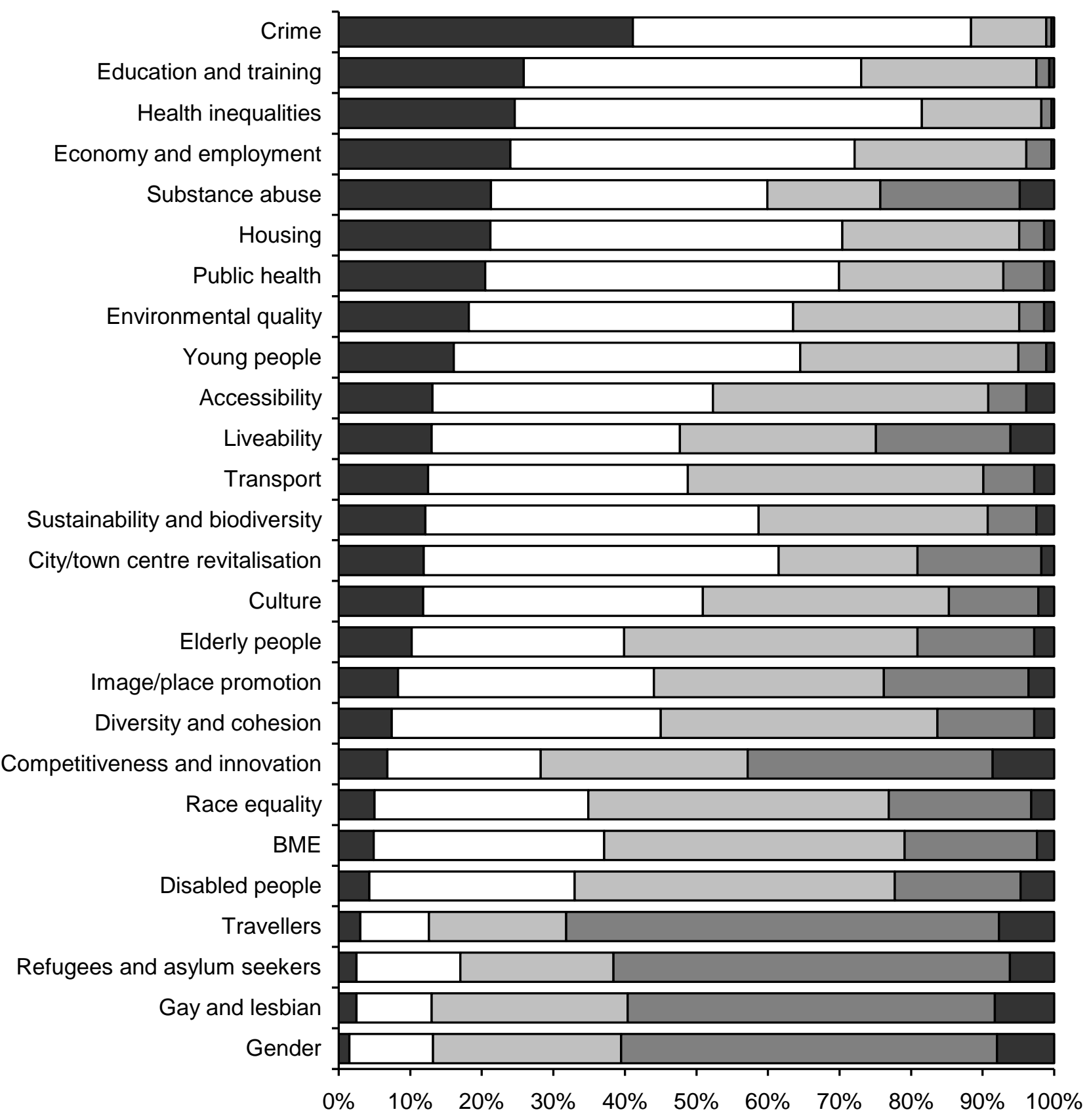

Achieved measurable outputs/outcomes $\square$ Joint strategy/activity

$\square$ On the LSP agenda but no action as yet $\square$ Issue not addressed

$\square$ Don't know 


\section{TP4 Outcomes: In doing so, service delivery and governance gains occur because agencies have a better understanding of what the community wants and work together to deliver.}

Figure 4 shows progress that LSPs consider they have made in delivering outcomes. Overall, partnerships believe that very significant progress is being made in many areas, especially considering that many LSPs have been established for a limited time and the initial expectation was that they would often need some time to bed down.

In evaluating the progress of LSPs in delivering outcomes, we make a distinction between process outcomes, governance or institutional outcomes and service outcomes. Much of the activity of LSPs still centres on what can be called 'process outcomes' - working more closely with partners, sharing information and staff resources, and financial collaboration via pooled funding of activity. There has been good progress on some of these issues but at the same time there are many LSPs yet to make progress in these areas. If these are indeed important preconditions for LSPs to make real progress towards service and governance outcomes, the implication must be that for numbers of LSPs significant levels of outcomes may still be some way off.

Local governance outcomes include the development of a collective vision and agreed strategy; widening the range of interests involved in local decision making; creating a stronger local voice; improving the perceived legitimacy of local governance; and exercising more effective influence locally and nationally. As noted above, the development of a collective vision and co-ordinated strategy stands out as the predominant issue on which major progress is claimed by LSPs - yet more detailed 
case study evidence suggests that in some cases, consensus exist only at the level of rhetoric (Fuller, 2006). Many LSPs also claim to have made some progress on others of these issues, though only very limited numbers consider that they have yet made major progress.

The third category of potential areas of progress relate to outcomes in terms of service improvements: delivering services delivered in ways which conform to the Community Strategy priorities and government's floor targets to better to meet community needs, especially in priority neighbourhoods. As is the case in relation to progress towards better governance, the overall picture is that substantial numbers of LSPs claim to have made some progress towards service improvement, although only relatively small proportions yet claim to have made major progress. Figure 3 shows that a number of issues stand out where significant numbers of LSPs claim to be achieving measurable outputs/outcomes. These are led by crime, but also include education, training, employment and health. These tend to be the areas associated with government floor targets and key neighbourhood renewal priorities. At the other end of the spectrum, there are certain issues which significant numbers of LSPs are not addressing at all. These include, for at least one third of all LSPs, competitiveness and innovation (distinguished from economic development and employment); gay and lesbian and gender issues; refugees and asylum seekers and travellers - despite the fact that these would seem to be important concerns for government policies on the economy and on social inclusion and community cohesion. 


\section{Figure 4: Progress by LSPs}

Collective vision and co-ordinated strategy

Understanding partners' priorities

Strategic application of NRF to mainstream services

Building a stronger and more united local voice

Sharing data and information

Ensuring partners' policies, plans, targets, PIs reflect CS priorities

Widening the range of interests involved in local decision-making

Services better meet needs in priority neighbourhoods

Innovation and dissemination of good practice

Levering in additional resources

Meeting floor targets

Services delivered better to meet community needs

More effective influence on council decisions

Joint funding of projects

More effective influence on regional and national issues

Sharing staff resources

Bringing marginalised social groups into the decision-making process

Greater legitimacy in the eyes of the community

Pooling budgets

Mapping partners' spending programmes
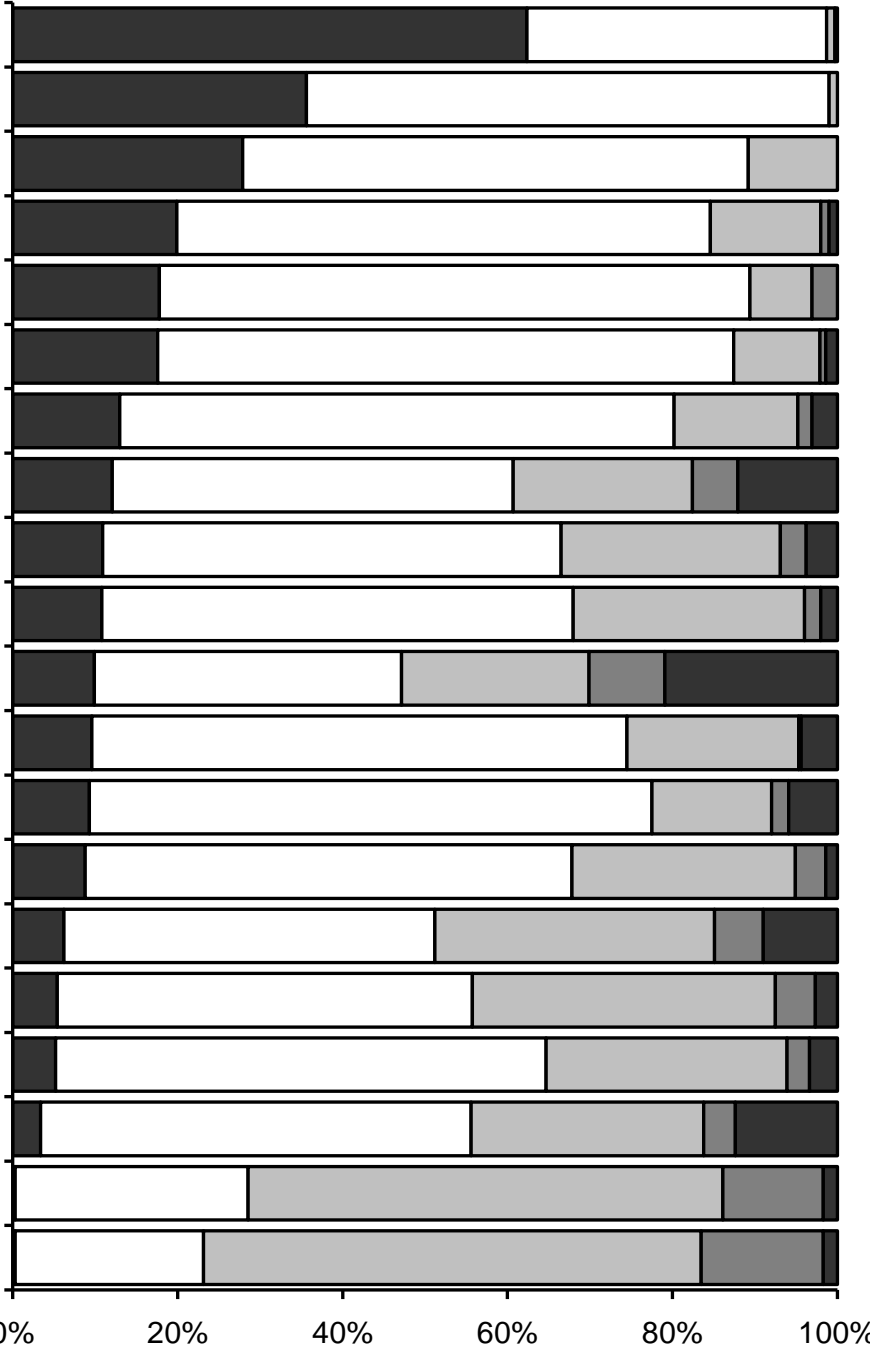

Major progress by LSP

$\square$ No progress by the LSP

$\square$ Some progress by LSP

$\square$ Don't know/ not applicable

$\square$ Not a priority for the LSP 
Performance management is seen by government as crucial for LSPs to demonstrate that they are delivering sustainable community strategies and that in delivering them, they are also delivering outcomes valued by local citizens. The upside of performance management is that it challenges partnerships to show that they are making a difference. The downside is that it can embed a managerialist, or technocratic approach to delivery, marginalising the public view and more theoretical and contextual analysis of what constitutes 'progress' (Clarke and Newman, 1997). Underlying debate about performance management is the status of the LSP as a nonstatutory, non-executive organisation, and the questions of how far an LSP can performance manage its partners, and whether performance management inhibits or encourages partnership working.

\section{TP5 The value added by the LSP creates a virtuous cycle...}

An important issue both for LSPs and for the evaluation is to be able to show what contribution the LSP has made to outcomes and whether or not they would have occurred without the LSP. Some LSPs can now identify, with some degree of precision, ways in which the LSP is enabling positive outcomes to occur which would - at least - have been more difficult in the absence of the LSP. However in other cases LSPs are still find this difficult, and some partners are clearly dubious whether the LSP is adding value. In some cases there is a suggestion that LSPs may merely be 'badging' outcomes achieved by partners (Fuller, 2006). Those LSPs which are not yet using some form of performance management seem to find it hardest to identify added value. 
Overall, perhaps unsurprisingly, the evaluation demonstrated major differences in the progress LSPs have made. This suggested the need to modify the original ToC model to accommodate the possibility of both 'virtuous' and 'vicious' circles. The 'virtuous' circle occurs when LSPs become deeply embedded in the local governance landscape as sustainable institutions and conform broadly with the aspirations for partnership working in New Labour philosophy. The vicious circle occurs when governmental aspirations are thwarted and a destructive cycle ensues representing a challenge perhaps not only to LSPs but to the partnership mode of governance per se, rendering it 'unsustainable' as an institutional fix for the contemporary challenges of 'governance'.

\section{The virtuous circle}

The virtuous circle is likely to be rooted, in the first place, in a positive local context a history of strategic partnership predating the LSP, and of trust and good working relationships between partners. Positive local contexts are also those in which the geographical area covered by the LSP is a good 'fit' with both socio-economic patterns, and with the boundaries of key partners, and in which there is a stable local political environment.

A positive local context of this kind is likely to make it easier for the LSP to recruit and engage members - partners will want to engage with the LSP rather than needing convincing or persuading. But engaging partners will also be easier when there is effective local leadership - from the local authority, but also from other partners, so that there is an atmosphere of collective leadership, rather than the LSP being driven by the local authority. In particular, perhaps, the voluntary and community sectors 
will recognise that their involvement is valued by other partners (Balloch and Taylor, 2001).

Alongside the leadership exercised by leading Board or Executive members, the role of the partnership's staff team is crucial in setting up and running the processes through which the LSP works in an inclusive, professional and efficient manner. An effective staff team will communicate well with partners, regional and sub-regional partners, the GO and other stakeholders, and will ensure that strong performance management arrangements are used proactively to monitor and evaluate performance and drive progress. Adequate resources will be available to manage and run the LSP - probably primarily from the local authority, but other partners will contribute because they recognise the value of the LSP to their own objectives.

The LSP will have played a leading role in the development of the Community Strategy (and the LNRS in NRF areas), ensuring that it is widely owned and is seen to add real value to the strategies of partners. The CS and LNRS will be driving the activity of the LSP, and as both these strategies and those of partners are reviewed and updated there will be increasing synergy between them and this will lead to opportunities to modify partners' spending plans to meet joint priorities, and to significant progress involving active collaboration among partners to meet local floor targets and other priorities. Performance management arrangements will be an integral part of the LSPs development and improvement.

As progress is made it will increasingly have a self-sustaining or path-dependent effect, as partners and stakeholders recognise the value which the LSP adds and 
commit themselves more fully. Effective publicity will ensure that the role of the LSP in the wider local governance system is recognised well beyond those who contribute directly to it. Partners will increasingly recognise the value of the LSP in lobbying on behalf of the area with regional and national government. When asked about the added value which the LSP brings, partners will be able to quote concrete examples of positive outcomes and impacts, and will consider that, in the words of one individual 'if the LSP did not exist we would have to invent it'.

\section{The vicious circle}

The vicious circle is most commonly found in local contexts where there is no tradition of strategic partnership and little trust between key partners, some of whom may not see how an LSP covering the area in question has strategic relevance to them. Political turbulence in the local authority may inhibit the local authority's ability to give sustained community leadership, and other key partners may also be preoccupied with their own concerns.

In such contexts, it will be difficult to secure the involvement in the LSP of key partners, and engagement by partners will be limited and superficial. The leadership of the LSP will be ineffective - perhaps because many partners think the local authority is too dominant, or equally because it is not supportive enough. In the absence of local authority leadership, other partners may adopt instrumental or defensive attitudes to the LSP. There will be little evidence that partners are committed to changing their own organisations in accordance with LSP priorities. 
Instead of the LSP taking the lead in developing the CS and LNRS, its role may have been little more than one of 'signing off' these documents, and as a result the strategies are likely to be superficial, failing to engage with the priorities of partners. As a result, the CS and LNRS will not drive the activity of the LSP or of key partners, and the LSPs activity will not add up to more than a disparate bundle of actions not rooted in the mainstream. In NRF areas, partners may see the LSP as little more than an opportunity to access NRF funding.

In this scenario, the LSP is likely to suffer from inadequate staffing and resourcing (Geddes, 2006). Lack of commitment to the LSP will mean that neither the local authority nor other partners are willing to commit substantial resources to the LSP, and consequently a small staff team, often perceived to have little autonomy from the local authority, will not give the LSP sufficient capacity (Johnson and Osbourne, 2003). Performance management may be lacking or may exist in principle but without serving as a real driver of improvement. With the failure to develop a strong strategic focus which engages partners, the LSP may come to be seen as a talking shop, or as a bureaucratic process which consumes time without leading to outcomes. Partners will increasingly question the value of the LSP, and devote more time to their own organisations or to other partnerships which seem to offer more added value.

Identification of these virtuous and vicious circles is not intended to imply that LSPs need become locked in one or the other. Partnerships may experience progress in some areas but face difficulties in others. Some LSPs have made progress along the path of virtue which has then faltered, while others have made recent progress after a slow start. It may be possible for LSPs to 'break in' to the virtuous circle or 'break 
out' of the vicious circle at various points, although theories of path dependency suggest that this may be difficult (Pierson, 2000; Davies, 2004). Thus, for example, strong local leadership can build a supportive local context for the LSP in areas where this does not already exist, while failure to institute efficient working practices can undermine initial partner commitment. The purpose of identifying these trajectories is rather to highlight on the one hand those factors which in combination tend to make for an effective LSP, and those in which the LSP is unlikely to succeed.

The identification, via an extension of the theory of change, of both virtuous and vicious circles of LSP development in this way helps to highlight not only those factors which either drive progress or constitute barriers to it, but the complexity of policy initiatives such as LSPs. Limited political commitment to the LSP, or the limited engagement of partners, reflect some of the tensions within the wider agendas of public service reform and local government modernisation which can play out in LSPs, and which a fully developed theory of change should try to acknowledge.

\section{Conclusion - LSPs: theory and practice}

The national evaluation has flagged up some of the most crucial issues facing LSPs, along with the wide local variation in the success with which this national initiative has been implemented. It suggests that the future of LSPs is not easy to predict. The current government consultation on the future of LSPs may provide an opportunity to tackle some of the issues highlighted here and to institute measures to bring poorly performing LSPs up towards the standards of the more successful ones. But the future context is not likely to get easier, as pressures on LSPs are now likely to be exacerbated by the advent of Local Area Agreements. LAAs may well be an 
opportunity for the stronger LSPs to demonstrate that they have the capacity to add value, enhancing their role as the forum within which partners come together to agree and deliver on local priorities, and enabling them more effectively to influence the mainstream policies of partner agencies. But LAAs also represent a major challenge to local partnership working, and many LSPs lack the capacity and structures for rapid and effective decision-making which the LAA will require. LAAs may highlight tensions between efficient decision making and wide participation and weaknesses in accountability and communication. However, underlying the challenges to LSPs represented by new initiatives such as LAAs, the evaluation highlights fundamental issues about the concept and practice of 'partnership governance' - from the capacity of partnerships as institutions with wide remits but limited resources, to their ambiguous relationship to local democratic accountability.

The theory of change approach has been important in helping the evaluation to grapple with the complexity of LSPs. The model, in succeeding iterations, has proved to be both robust and flexible, developing in a dynamic way with the progress of the evaluation. However, certain issues also need to be recognised. In the first place, the theory of change has been used primarily within the research team ${ }^{6}$. The understandings reflected in it were confirmed through seminars with policy makers and practitioners at an early stage, and seem to have been widely accepted as further research outputs have been disseminated. However, the theory of change has not been actively utilised in dialogue between the evaluation team and LSPs themselves in quite the way in which the North American originators of the approach regarded as important - 'the expectation that all affected stakeholders will be involved in developing, agreeing, monitoring and evaluating a relevant theory for the 
intervention, and the assumption that widespread stakeholder involvement will extend ownership of the intervention to achieve 'total ownership' (Sullivan and Stewart, 2004). Indeed, the way in which we have developed the model through the elaboration of virtuous and vicious circles embodied recognition that some stakeholders take a critical view of LSPs. An important conclusion would seem to be that, as Sullivan and Stewart discuss, a theory of change is likely to be contested if it concerns a government policy which is itself contested to some degree, and that something like the 'virtuous and vicious circles' approach which we have developed can go some way to recognise the contested nature of policy.

Secondly, the ToC lies in the domain of middle level theory, which focuses on the organisational/institutional level, between on the one hand, society as a structured entity, and the individual, with powers of agency within specific social contexts. As Sanderson (2000) for example recognises, it is important to 'embed' this meso-level, organisational focus in its social, political and economic contexts. Further development of this model would mean addressing questions of power relationships (both between central and local actors and between different actors at the local level) which underlie, for example, issues about the inclusiveness of LSPs and the relationship between the 'national context' and local initiative.

A final difficulty with this model is that it may appear to implicate government in a naïvely rationalistic policy cycle approach (Davies, 2005). On the one hand, government leaves itself open to this with its emphasis on evidence based policy making and its managerialist approach to network policy. In this model, as Skelcher et al put it (2005: 586) 'technical expertise is privileged and decisions proceed 
through a rational process little impacted by the political world'. On the other hand, Stoker sees New Labour as a fatalistic government, seeing 'all systems as capricious' and offering only 'modest prospects for effective coordination' (Stoker, 2002: 419). He continues: '[a]t the top of New Labour there is a widespread but not universal culture of paranoia that sees enemies all around' (Stoker, 2002: 432). This is not the place to adjudicate between rationalist and fatalist interpretations of New Labour. Both may be valid. However, this debate is a cautionary note that it may be imprudent to assign a rationalist perspective to government policy makers, and that theories of change predicated on a such a model of public policy need to recognize the limits to rationality in the evolution of policy. Indeed, the findings from the LSPs evaluation concerning the wide variations in local trajectories and the - so far at any rate - modest outcomes in many places add weight to this conclusion. 


\section{References}

Aulakh, S., Woolford, J., Smith, M. and Skelcher. C (2002) Accreditation of Local Strategic Partnerships (2001/02): An analysis and review of documentation. London: Neighbourhood Renewal Unit, Research Report 4.

Bailey, N. (2003) Strategic partnerships in England: The continuing search for collaborative advantage, leadership and strategy in urban governance. Planning Theory and Practice, Vol. 4 (4), 443-457.

Balloch, S. and Taylor, M. (Eds) (2001) Partnership Working: Policy and Practice. Bristol: Policy Press.

Chen HT, 1990, Theory driven evaluations, London: Sage.

Clarke and Newman (1997) The Managerial State. London: Sage

Connell JP and Kubisch AC, 1998, Applying a theory of change approach to the evaluation of comprehensive community initiatives: Progress, prospects and problems, in Fulbright-Anderson $\mathrm{K}$ et al (Eds) New approaches to evaluating community initiative, Vol 2, Theory, measurement and analysis, Aspen Institute, Washington DC, 15-44.

Davies J S, 2004, Conjuncture or Disjuncture? An Institutionalist Analysis of Local Regeneration Partnerships in the UK. International Journal of Urban and Regional Research 28(3) 570-585

Davies J S, 2005, The antinomies of 'third way' institution building: the case of local strategic partnerships. $35^{\text {th }}$ Annual Meeting of the Urban Affairs Association, Salt Lake City, Utah, April 2005.

Davies J S, 2006, The limits of partnership for democratic inclusion and the case for exit. $36^{\text {th }}$ Annual Meeting of the Urban Affairs Association, 19-22 April 2006, Montreal, Quebec.

Department of the Environment, Transport and the Regions, 2001 Local Strategic Partnerships, Government Guidance, London: DETR.

Fuller, C. (2006) State rescaling, multi-level governance and the search for joined-up local governance. Geoforum, (Under review).

Fuller, C. and Geddes, M. 'Local governance under neo-liberalism: Local state restructuring and processes of scalar transformation in England', Antipode, (Preparing for resubmission).

Geddes M (2006) Theories of Change: Issues Paper. London: ODPM

Geddes, M. (2006) Partnership and the limits of local Governance. International Journal of Urban and Regional Research. 30: 1. 
Geddes M and Benington J, 2001, Local partnership and social exclusion in the European Union: New modes of local governance? London: Routledge.

Hastings, A. (2003) Strategic, multi-level neighbourhood regeneration: an outwardlooking approach at last? In R. Imrie and M. Raco Urban Renaissance? New Labour, community and urban policy. Bristol: Policy

Johnson, C. and Osbourne, S. (2003) Local strategic partnerships, neighbourhood renewal and the limits of co-governance. Public Money and Management, July, 147154.

Jones and Ward (2002) Excavating the logic of British Urban Policy: Neoliberalism as the "crisis of crisis-management." In N. Brenner and N. Theodore (2002) Spaces of Neoliberalism: Urban Restructuring in North America and Western Europe. Oxford: Blackwell.

Mackenzie M and Blamey A, 2005, The practice and the theory: Lessons from the application of a theories of change approach, Evaluation, 11, 151-168.

Marsh D and Rhodes R A W, 1992, Implementing Thatcherite policies: an audit of an era. Philadelphia, Open University Press.

ODPM, 2006, Local Strategic Partnerships: Shaping their future. London: Office of the Deputy Prime Minister.

Pierson P, 2000, Increasing returns, path dependency and the study of politics. American Political Science Review 94(2), 251-267.

Sanderson I, 2000, Evaluation in complex policy systems, Evaluation, 6, 4, 433-454.

Skelcher C, Mathur N and Smith M, 2005, The public governance of collaborative spaces: Discourse, design and democracy. Public administration 83(3) 573-596

Skelcher C, 2005, Jurisdictional integrity, polycentrism, and the design of democratic governance. Governance. 18(1) 89-110

Sorensen E and Torfing J, 2005, The democratic anchorage of governance networks. Scandanavian political studies 28(3) 195-218

Stoker G, 2002, 'Life is a Lottery: New Labour's Strategy for the Reform of Devolved Governance' in Public Administration 80(3), 417-434

Sullivan H, Barnes M and Matka E, 2002, Building collaborative capacity through theories of change: Early lessons from the evaluation of Health Action Zones in England, Evaluation, 8, 205-226.

Sullivan H, Gillanders G, Goss S and Steele J, 2003, Developing a 'Theory of Change' to evaluate Local Public Service Agreements, LPSA Evaluation Working Paper, London, ODPM. 
Sullivan H and Stewart M, 2006, Who owns the theory of change? Evaluation, 12, 2, forthcoming.

Sullivan H and Skelcher C, 2002, Working across boundaries: Collaboration in the public services. Basingstoke: Palgrave.

Weiss C, 1995, Nothing as practical as good theory: Exploring theory-based evaluation for comprehensive community initiatives for children and families, in Connell JP et al (Eds) New approaches to community initiatives, Vol 1Contents, methods and context, Washington DC, Aspen Institute. 


\section{Footnotes}

${ }^{1}$ Jointly commissioned by three ODPM research divisions (LRGRU, NRU and RAE) and the Department for Transport (DfT), the first 3 years of the programme was commissioned in March 2002, and has been undertaken by the Universities of Warwick, Liverpool John Moores, West of England, Bristol and the Office for Public Management. A Summative Evaluation of impacts and effectiveness is provisionally planned for $2006-2008$. The arguments and conclusions of this article are those of the authors, who were members of the evaluation team, but not necessarily of the whole team or of ODPM/DfT.

${ }^{2}$ The evaluation has produced more than $\mathbf{x x}$ published outputs. See www.odpm.gov.uk/localgov.

${ }^{3}$ However, it is clear that there are a number of ways of working with a TOC approach (even already within the group of LGMA evaluations, for example). Sullivan and Stewart raise a number of critical questions about the approach and its application in the UK compared to US contexts, especially whether it is important that the approach is shared with those involved in the programme under evaluation, not just by the evaluation team. It is relevant to note in this context that the approach was originally developed in the context of community-based initiatives, rather than national policy programmes.

${ }^{5}$ The evaluation does not, though, show conclusively whether or not strong partnership bureaucracies and generous resourcing add to capacity or not. .

${ }^{6}$ This is partly because of resource limitations within the evaluation, but also because there are important differences between the local community-based evaluations in which the idea of a theory of change approach was initially developed, and national policy initiatives such as LSPs. 